\title{
Taxonomic study of a chromomycin-producing strain and reclassification of Streptomyces cavourensis subsp. washingtonensis as a later synonym of Streptomyces griseus
}

\author{
Xuechang Wu, Yanping Wen, Chaodong Qian, Ou Li, Haihuang Fang \\ and Weifeng Chen
}

Correspondence

Xuechang Wu

shengwukexu@163.com

\author{
Institute of Microbiology, College of Life Sciences, Zhejiang University, Hangzhou 310012, \\ PR China
}

\begin{abstract}
A chromomycin-producing actinomycete, strain AP19, was isolated from a sample of faeces collected from Foping national nature reserve in China. Chemotaxonomic and morphological properties indicated that the novel isolate was a member of the genus Streptomyces.

Phylogenetic analyses based on an almost complete 16S rRNA gene sequence of the strain and on the 120-nt nucleotide variable $\gamma$-region of this molecule revealed that it was closely related to Streptomyces griseus ISP $5236^{\top}$ and Streptomyces cavourensis subsp. washingtonensis ATCC $27732^{\top}$. DNA-DNA relatedness values among these strains were above $70 \%$. Streptomyces cavourensis subsp. washingtonensis could be readily distinguished from Streptomyces cavourensis ATCC $14889^{\top}$ by differing BOX-PCR fingerprinting patterns, relatively low $16 \mathrm{~S}$ rRNA gene sequence similarity and a low DNA-DNA relatedness value. It is proposed, therefore, that Streptomyces cavourensis subsp. washingtonensis is a later synonym of Streptomyces griseus.
\end{abstract}

Conventional classification methods for the identification of species within the genus Streptomyces have mainly relied on the morphological and phenotypic characteristics of the organisms. During the last decade, molecular biological methods such as $16 \mathrm{~S}$ rRNA gene sequencing and BOX-PCR fingerprinting have had an increasing impact on streptomycete taxonomy (Kim \& Goodfellow, 2002; Kim et al., 2004; Lanoot et al., 2004; Saintpierre et al., 2003; Williams et al., 1983). Molecular systematic data show that the genus is clearly overspeciated (Hatano et al., 2003; Lanoot et al., 2002, 2004), as exemplified by the proposal that Streptomyces lipmanii LMG $20047^{\mathrm{T}}$, Streptomyces willmorei LMG $21046^{\mathrm{T}}$, Streptomyces griseus subsp. alpha LMG $19953^{\mathrm{T}}$ and Streptomyces griseus subsp. cretosus LMG $19946^{\mathrm{T}}$ should be recognized as heterotypic synonyms of Streptomyces microflavus LMG $19327^{\mathrm{T}}$ (Lanoot et al., 2005).

The present study describes the taxonomic position of a chromomycin-producing strain, AP19, isolated from faeces. The sample of faeces was collected from Foping national nature reserve, Shanxi province, China.

\footnotetext{
Abbreviation: DAP, diaminopimelic acid.

The GenBank/EMBL/DDBJ accession number for the 16S rRNA gene sequence of strain AP19 is EF466100.

A figure showing the BOX-PCR patterns of strain AP19 and other closely related strains is available with the online version of this paper.
}

Phenotypic and phylogenetic data showed that the novel strain was closely related to Streptomyces cavourensis subsp. washingtonensis NRRL $\mathrm{B}-8030^{\mathrm{T}}$ and Streptomyces griseus ISP $5236^{\mathrm{T}}$. In the phylogenetic tree based on $16 \mathrm{~S}$ rRNA gene sequences, these strains formed a clade in the Streptomyces tree, indicating that they could belong to the same taxon.

Strain AP19 was isolated on Gause's synthetic agar plates supplemented with $2 \mu \mathrm{g}$ potassium dichromate. The plates were seeded with a faeces sample suspension and incubated at $28{ }^{\circ} \mathrm{C}$ for 14 days. The isolate was maintained on Gause's synthetic slopes at $4{ }^{\circ} \mathrm{C}$ and as glycerol suspensions $(20 \%, \mathrm{v} / \mathrm{v})$ at $-20{ }^{\circ} \mathrm{C}$. All other strains used in this study, namely Streptomyces alboviridis NRRL B-3633 ${ }^{\mathrm{T}}$, Streptomyces cavourensis ATCC $14889^{\mathrm{T}}$, S. cavourensis subsp. washingtonensis ATCC $27732^{\mathrm{T}}$, Streptomyces erumpens NRRL B-3163 ${ }^{\mathrm{T}}$, Streptomyces fulvorobeus NRRL B$24329^{\mathrm{T}}$, Streptomyces griseus AS $4.1419^{\mathrm{T}}$, S. griseus ATCC 13273, S. griseus subsp. solvifaciens NRRL B- $1561^{\mathrm{T}}$ and Streptomyces microflavus AS $4.1428^{\mathrm{T}}$, were grown on medium 65 agar $(0.4 \% \mathrm{w} / \mathrm{v}$ glucose, $0.4 \%$ w/v yeast extract, $1 \% \mathrm{w} / \mathrm{v}$ malt extract, $0.2 \% \mathrm{w} / \mathrm{v} \mathrm{CaCO}_{3}$; final $\mathrm{pH}$ 7.2) and incubated at $30{ }^{\circ} \mathrm{C}$. For large-scale strain preparation, a $250 \mathrm{ml}$ flask with $50 \mathrm{ml}$ medium 65 broth $(0.4 \% \mathrm{w} / \mathrm{v}$ glucose, $0.4 \% \mathrm{w} / \mathrm{v}$ yeast extract, $1 \% \mathrm{w} / \mathrm{v}$ malt extract; final $\mathrm{pH}$ 7.2) was shaken for $36 \mathrm{~h}$ at $30{ }^{\circ} \mathrm{C}$. 
The morphological characteristics of strain AP19 grown on inorganic salt/starch agar at $28{ }^{\circ} \mathrm{C}$ for 14 days were observed by light microscopy and scanning electron microscopy. The cultural, physiological and biochemical characteristics of the tested strains were determined as described by Williams et al. (1983). The diaminopimelic acid (DAP) isomer and whole-organism sugars pattern were analysed according to the method of Hasegawa et al. (1983). The G +C content of the DNA of the novel strain was determined using the thermal denaturation method (Marmur \& Doty, 1962).

Genomic DNA was extracted and the 16S rRNA gene sequence was amplified as described by Chun \& Goodfellow (1995). The PCR products were ligated into the PCR2.1-TOPO vector and transformed into Escherichia coli TOP 10. The 16S rRNA gene sequence of strain AP19, inserted into the plasmid vector, was sequenced on a model 3730 Applied Biosystems DNA sequencer.

The sequence was analysed along with the sequences of closely related reference organisms retrieved from the DDBJ/EMBL/GenBank databases. Sequence data were aligned with CLUSTAL_X software, version 1.8 (Thompson et al., 1997). Phylogenetic trees were constructed by using neighbour-joining (Saitou \& Nei, 1987), minimum-evolu- tion (Edwards \& Cavalli-Sforza, 1963) and maximumparsimony (Kluge \& Farris, 1969) algorithms with the MEGA 3 software package (Kumar et al., 2004). Evolutionary distance matrices were generated as described by Kimura (1980). Tree topologies were evaluated by bootstrap analyses based on 1000 resamplings (Fig. 1). The partial sequence covering the variable $\gamma$-region $(120 \mathrm{nt}$, positions 158-277 according to the E. coli numbering system) of the 16S rRNA gene sequence of strain AP19 was also compared with the corresponding nucleotide sequences of type strains of the genus Streptomyces retrieved from GenBank. A phylogenetic tree based on these partial sequences was constructed using the neighbour-joining algorithm (Saitou \& Nei, 1987) (Fig. 2).

BOX-PCR fingerprint patterns were analysed as described by Lanoot et al. (2004), apart from some modifications in the electrophoresis conditions. A $25 \mu \mathrm{l}$ sample mixed with $5 \mu \mathrm{l}$ loading dye $(6 \times)$ was loaded on a $2.5 \%$ agarose gel (Biowest Agar, $10 \times 10 \mathrm{~cm}$ ). Every fourth well was loaded with $5 \mu \mathrm{l}$ molecular ruler $(200 \mathrm{bp})$. Electrophoresis was performed using $90 \mathrm{~V}, 60 \mathrm{~mA}$ for $210 \mathrm{~min}$ in $0.5 \times \mathrm{TBE}$ (0.54\% Tris, $0.27 \%$ boric acid, $2 \mathrm{ml} 0.5$ M EDTA; $\mathrm{pH} 8.0$ ).

The chemical and morphological properties of isolate AP19 were consistent with its assignment to the genus

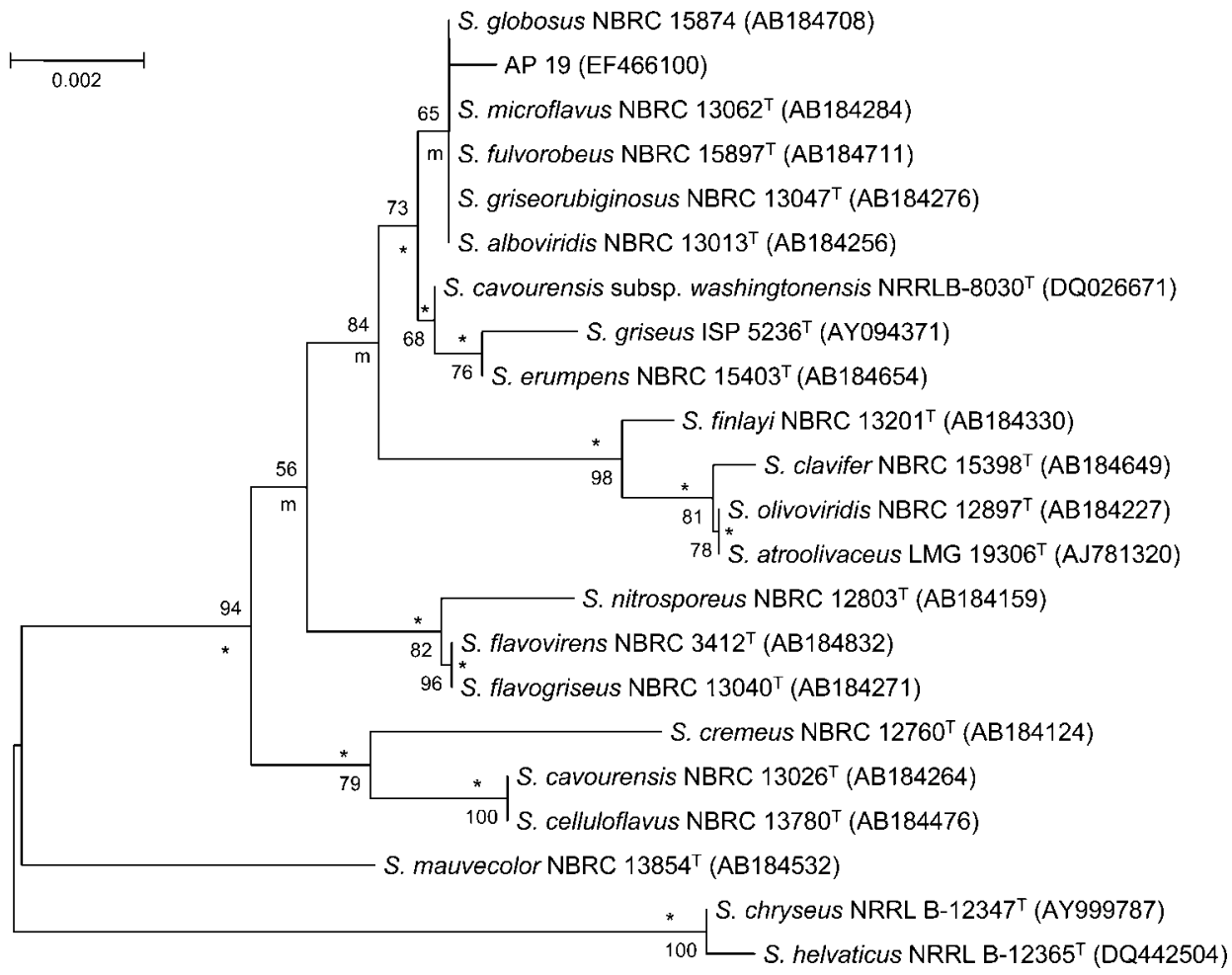

Fig. 1. Phylogenetic tree based on $16 \mathrm{~S}$ rRNA gene sequences from strain AP19 and other related organisms. The tree was constructed using the neighbour-joining algorithm. Asterisks indicate branches that were recovered using the minimumevolution and maximum-parsimony algorithms; $m$ indicates branches that were also formed when minimum-evolution treemaking algorithm was used. Bootstrap values (>50\%) based on 1000 replications are shown at nodes of the tree. Bar, 0.002 substitutions per nucleotide position. 


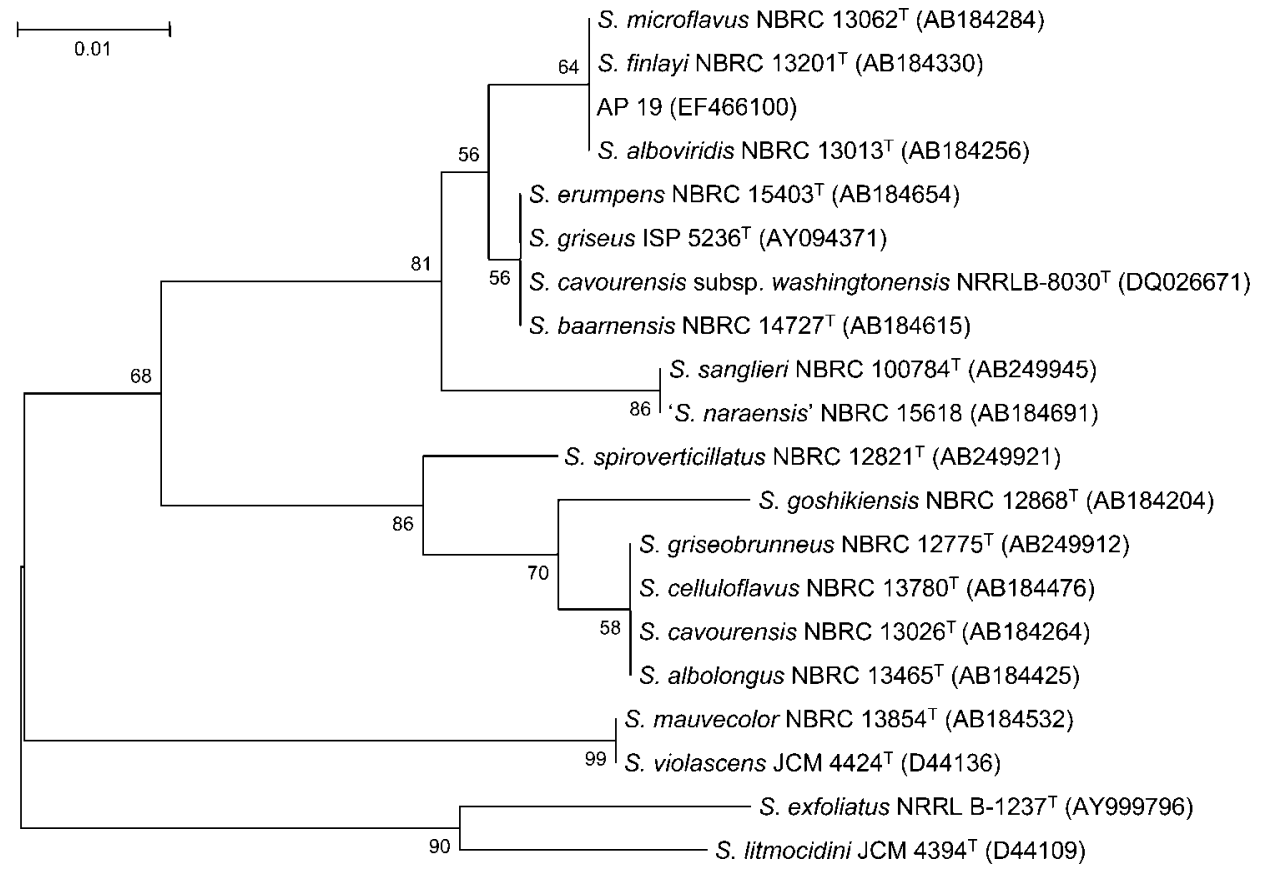

Fig. 2. Neighbour-joining tree based on the variable $\gamma$-region (120 nt, positions 158-277) of the $16 \mathrm{~S}$ rRNA gene of strain AP19 and other related species of the genus Streptomyces. Evolutionary distance matrices were generated as described by Kimura (1980). Bootstrap values (>50\%) based on 1000 replications are shown at nodes of the tree. Bar, 0.01 substitutions per nucleotide position.

Streptomyces. It formed extensive branching substrate mycelium and aerial hyphae with smooth-surfaced spores in rectiflexibile spore chains. DAP analysis revealed the presence of LL-diaminopimelic acid in the cell-wall peptidoglycan. No characteristic sugar was detected in the whole-cell hydrolysates. The $\mathrm{G}+\mathrm{C}$ content of the genomic DNA of strain AP19 was $71 \mathrm{~mol} \%$.

An almost complete 16S rRNA gene sequence (1478 nt) was determined for the novel strain. Primary sequence analysis with sequences of representatives of the family Streptomycetaceae confirmed that the novel isolate was closely related to species of the genus Streptomyces. In the phylogenetic tree based on almost complete 16S rRNA gene sequences (Fig. 1), sequence similarity values between strain AP19 and its nearest neighbours, namely Streptomyces griseorubiginosus NBRC $13047^{\mathrm{T}}$, S. alboviridis NBRC $13013^{\mathrm{T}}$, S. globosus NBRC 15874, Streptomyces microflavus NBRC $13062^{\mathrm{T}}$ and Streptomyces fulvorobeus NBRC $15897^{\mathrm{T}}$, were $99.93 \%$ ( $1 \mathrm{nt}$ difference at 1476 sites), $99.93 \%$ (1 nt difference at 1475 sites), $99.93 \%$ (1 nt difference at 1473 sites), $99.93 \%$ (1 nt difference at 1478 sites) and $99.86 \%$ (2 nt differences at 1472 sites). Besides the strains mentioned above, two strains that shared many phenotypic characteristics with strain AP19, S. cavourensis subsp. washingtonensis NRRL B-8030 ${ }^{\mathrm{T}}$ and S. griseus ISP $5236^{\mathrm{T}}$, also showed high $16 \mathrm{~S}$ rRNA gene sequence similarities of $99.93 \%$ ( $1 \mathrm{nt}$ difference at 1478 sites) and $99.65 \%$ (5 nt differences at 1448 sites), respectively.
BOX-PCR fingerprinting has been reported as a powerful tool to distinguish finer taxonomic relationships in the genus Streptomyces (Lanoot et al., 2004). The BOX-PCR fingerprinting patterns of strain AP19 and the closely related strain, S. cavourensis subsp. washingtonensis ATCC $27732^{\mathrm{T}}$ were very similar (see Supplementary Fig. S1 in IJSEM Online). These two strains formed a phylogenetic cluster, joining the phylogenetic clade comprising S. griseus AS $4.1419^{\mathrm{T}}$, S. griseus ATCC 13273 and S. griseus subsp. solvifaciens NRRL B-1561 ${ }^{\mathrm{T}}$. It was also evident that strain AP19 and S. cavourensis subsp. washingtonensis ATCC $27732^{\mathrm{T}}$ were separated from the nearest phylogenetic neighbours, S. alboviridis NRRL B- $3633^{\mathrm{T}}$, S. microflavus AS $4.1428^{\mathrm{T}}$, S. erumpens NRRL B- $3163^{\mathrm{T}}$ and S. fulvorobeus NRRL B-24329 ${ }^{\mathrm{T}}$. Furthermore, distinct BOX-PCR fingerprinting patterns were found between $S$. cavourensis ATCC $14889^{\mathrm{T}}$ and S. cavourensis subsp. washingtonensis ATCC $27732^{\mathrm{T}}$. This was consistent with the relatively low levels of $16 \mathrm{~S}$ rRNA gene sequence similarity (98.9\%) between these strains and the fact that they belonged to different clusters in the phylogenetic tree based on 16S rRNA gene sequences. These data indicate that strains AP19 and S. cavourensis subsp. washingtonensis ATCC $27732^{\mathrm{T}}$ can be classified as S. griseus.

A DNA-DNA hybridization study provided further evidence for the taxonomic classification of strain AP19. High DNA-DNA relatedness values, in the range from 75.2 to $94.2 \%$, were found between strain AP19, S. cavourensis 
Table 1. DNA-DNA reassociation values between strain AP19 and some related species of the genus Streptomyces

\begin{tabular}{|c|c|c|c|c|}
\hline \multirow[t]{2}{*}{ Strain } & \multicolumn{4}{|c|}{ Hybridization (\%) with labelled DNA from: } \\
\hline & 1 & 2 & 3 & 4 \\
\hline 1. AP19 & 100 & & & \\
\hline 2. S. griseus ATCC 13273 & 94.2 & 100 & & \\
\hline 3. S. cavourensis subsp. washingtonensis ATCC $27732^{\mathrm{T}}$ & 75.2 & 80.1 & 100 & \\
\hline 4. S. cavourensis ATCC $14889^{\mathrm{T}}$ & 54.8 & 64.3 & 51.3 & 100 \\
\hline
\end{tabular}

Table 2. Phenotypic characteristics of strain AP19 and some related strains

Strains: 1, AP19; 2, S. cavourensis subsp. washingtonensis ATCC $27732^{\mathrm{T}}$; 3, S. griseus ATCC 13273; 4, S. cavourensis ATCC $14889^{\mathrm{T}}$. All strains produced white aerial spore mass on oatmeal agar and had a rectiflexibile spore chain arrangement and a smooth spore surface. For $S$. cavourensis ATCC $14889^{\mathrm{T}}$, melanin was produced during tests for the degradation of casein, guanine, L-tyrosine and xanthine. + , Positive; - , negative.

\begin{tabular}{|lcccc|}
\hline Characteristic & $\mathbf{1}$ & $\mathbf{2}$ & $\mathbf{3}$ & $\mathbf{4}$ \\
\hline Melanin production & - & - & - & + \\
Production of diffusible pigments & Greenish yellow & Greenish yellow & Yellow & Pale orange-yellow \\
Degradation of: & & & + & - \\
$\quad$ Cellulose & + & + & + & - \\
Guanine & + & + & + & - \\
Xanthine & + & + & Chromomycin \\
Growth on sole carbon source $(1.0 \%, \mathrm{w} / \mathrm{v}):$ & Chromomycin & Chromomycin & Flavensomycin \\
Adonitol & & & \\
Production of antibiotic & & &
\end{tabular}

subsp. washingtonensis ATCC $27732^{\mathrm{T}}$ and S. griseus ATCC 13273 (Table 1). The DNA-DNA relatedness value between S. cavourensis subsp. washingtonensis ATCC $27732^{\mathrm{T}}$ and $S$. cavourensis ATCC $14889^{\mathrm{T}}$ was $51.3 \%$, which is below the $70 \%$ cut-off point for recognition of genomic species (Wayne et al., 1987). Furthermore, S. cavourensis subsp. washingtonensis ATCC $27732^{\mathrm{T}}$ could be distinguished from S. cavourensis ATCC $14889^{\mathrm{T}}$ by distinct BOX-PCR fingerprinting patterns, different cultural characteristics on standard media and a set of physiological features (Table 2). Phylogenetic trees based on 16S rRNA gene sequences and the $120 \mathrm{nt} \gamma$-region of the 16S rRNA gene sequence in which $S$. cavourensis subsp. washingtonensis ATCC $27732^{\mathrm{T}}$ and S. griseus ISP $5236^{\mathrm{T}}$ formed a clade, distinct from S. cavourensis ATCC $14889^{\mathrm{T}}$, also supported this assignment (Figs 1, 2).

Based on the genotypic and phenotypic evidence, Streptomyces cavourensis subsp. washingtonensis ATCC $27732^{\mathrm{T}}$ should be considered as a later heterotypic synonym of Streptomyces griseus ISP $5236^{\mathrm{T}}$ and strain AP19 should also be assigned to this taxon.

\section{Acknowledgements}

This contribution was supported by grants from the National Nature Science Foundation of China. The authors are grateful to Dr Ying Huang (Chinese Academy of Sciences, China) for her help in the identification of strain AP19 and to Mrs Zhiyun Wang for her assistance in strain isolation. The authors are indebted to Dr Labeda (Microbial Genomics and Bioprocessing Research Unit, America) for providing some of the type strains.

\section{References}

Chun, J. \& Goodfellow, M. (1995). A phylogenetic analysis of the genus Nocardia with 16S rRNA gene sequences. Int J Syst Bacteriol 45, 240-245.

Edwards, A. W. F. \& Cavalli-Sforza, L. L. (1963). The reconstruction of evolution. Heredity 18, 553.

Hasegawa, T., Takizawa, M. \& Tanida, S. (1983). A rapid analysis for chemical grouping of aerobic actinomycetes. J Gen Appl Microbiol 29, 319-322.

Hatano, K., Nishii, T. \& Kasai, H. (2003). Taxonomic re-evaluation of whorl-forming Streptomyces (formerly Streptoverticillium) species by using phenotypes, DNA-DNA hybridization and sequences of gyrB, and proposal of Streptomyces luteireticuli (ex Katoh and Arai 1957) corrig., sp. nov., nom. rev. Int J Syst Evol Microbiol 53, 1519-1529.

Kim, S. B. \& Goodfellow, M. (2002). Streptomyces avermitilis sp. nov., nom. rev., a taxonomic home for the avermectin-producing streptomycetes. Int J Syst Evol Microbiol 52, 2011-2014.

Kim, S. B., Seong, C. N., Jeon, S. J., Bae, K. S. \& Goodfellow, M. (2004). Taxonomic study of neutrotolerant acidophilic actinomycetes isolated from soil and description of Streptomyces yeochonensis sp. nov. Int J Syst Evol Microbiol 54, 211-214.

Kimura, M. (1980). A simple method for estimating evolutionary rates of base substitutions through comparative studies of nucleotide sequences. J Mol Evol 16, 111-120. 
Kluge, A. G. \& Farris, J. S. (1969). Quantitative phyletics and the evolution of anurans. Syst Zool 18, 1-32.

Kumar, S., Tamura, K. \& Nei, M. (2004). MEGA3: integrated software for molecular evolutionary genetics analysis and sequence alignment. Brief Bioinform 5, 150-163.

Lanoot, B., Vancanneyt, M., Cleenwerck, I., Wang, L., Li, W., Liu, Z. \& Swings, J. (2002). The search for synonyms among streptomycetes by using SDS-PAGE of whole-cell proteins. Emendation of the species Streptomyces aurantiacus, Streptomyces cacaoi subsp. cacaoi, Streptomyces caeruleus and Streptomyces violaceus. Int J Syst Evol Microbiol 52, 823-829.

Lanoot, B., Vancanneyt, M., Dawyndt, P., Cnockaert, M., Zhang, J., Huang, Y., Liu, Z. \& Swings, J. (2004). BOX-PCR fingerprinting as a powerful tool to reveal synonymous names in the genus Streptomyces. Emended descriptions are proposed for the species Streptomyces cinereorectus, S. fradiae, S. tricolor, S. colombiensis, S. filamentosus, S. vinaceus and S. phaeopurpureus. Syst Appl Microbiol 27, 84-92.

Lanoot, B., Vancanneyt, M., Van Schoor, A., Liu, Z. \& Swings, J. (2005). Reclassification of Streptomyces nigrifaciens as a later synonym of Streptomyces flavovirens; Streptomyces citreofluorescens, Streptomyces chrysomallus subsp. chrysomallus and Streptomyces fluorescens as later synonyms of Streptomyces anulatus; Streptomyces chibaensis as a later synonym of Streptomyces corchorusii; Streptomyces flaviscleroticus as a later synonym of Streptomyces minutiscleroticus; and Streptomyces lipmanii, Streptomyces griseus subsp. alpha, Streptomyces griseus subsp. cretosus and Streptomyces willmorei as later synonyms of Streptomyces microflavus. Int J Syst Evol Microbiol 55, 729-731.

Marmur, J. \& Doty, P. (1962). Determination of the base composition of deoxyribonucleic acid from its thermal denaturation temperature. $J$ Mol Biol 5, 109-118.

Saintpierre, D., Amir, H., Pineau, R., Sembiring, L. \& Goodfellow, M. (2003). Streptomyces yatensis sp. nov., a novel bioactive streptomycete isolated from a New-Caledonian ultramafic soil. Antonie van Leeuwenhoek 83, 21-26.

Saitou, N. \& Nei, M. (1987). The neighbor-joining method: a new method for reconstructing phylogenetic trees. Mol Biol Evol 4, 406425.

Thompson, J. D., Gibson, T. J., Plewniak, F., Jeanmougin, F. \& Higgins, D. G. (1997). The CLUSTAL_X windows interface: flexible strategies for multiple sequence alignment aided by quality analysis tools. Nucleic Acids Res 25, 4876-4882.

Wayne, L. G., Brenner, D. J., Colwell, R. R., Grimont, P. A. D., Kandler, O., Krichevsky, M. I., Moore, L. H., Moore, W. E. C., Murray, R. G. E. \& other authors (1987). International Committee on Systematic Bacteriology. Report of the ad hoc committee on reconciliation of approaches to bacterial systematics. Int J Syst Bacteriol 37, 463-464.

Williams, S. T., Goodfellow, M., Alderson, G., Wellington, E. M., Sneath, P. H. \& Sackin, M. J. (1983). Numerical classification of Streptomyces and related genera. J Gen Microbiol 129, 1743-1813. 